\title{
Cluster Analysis for the Questionnaire Investigation on the Needs at Fuji Shopping Street in Fuji City
}

\author{
Yuki Higuchi ${ }^{1}$, Akane Okubo $^{2}$, Daisuke Suzuki ${ }^{3} \&$ Kazuhiro Takeyasu ${ }^{4}$ \\ ${ }^{1}$ Faculty of Business Administration, Setsunan University, Neyagawa, Osaka, Japan \\ ${ }^{2}$ NIHON University Junior College, Shizuoka, Japan \\ ${ }^{3}$ Fujisan Area Management Company, Shizuoka, Japan \\ ${ }^{4}$ College of Business Administration, Tokoha University, Shizuoka, Japan \\ Correspondence: Yuki Higuchi, Faculty of Business Administration, Setsunan University, Neyagawa, Osaka, \\ Japan.
}

Received: April 27, 2017

Accepted: May 8, 2018

Online Published: May 30, 2018

doi:10.20849/abr.v3i2.390

URL: https://doi.org/10.20849/abr.v3i2.390

\begin{abstract}
Shopping streets at local city in Japan became old and are generally declining. In this paper, we handle the area rebirth and/or regional revitalization of shopping street. We focus on Fuji city in Japan. Four big festivals are held at Fuji city (two for Fuji Shopping Street Town and two for Yoshiwara Shopping Street Town). Many people visit these festivals including residents in that area. Therefore a questionnaire investigation to the residents and visitors is conducted during these periods in order to clarify residents and visitors' needs for the shopping street, and utilize them to the plan building of the area rebirth and/or regional revitalization of shopping street. There is a big difference between Fuji Shopping Street Town and Yoshiwara Shopping Street Town. Therefore we focus Fuji Shopping Street Town in this paper. These are analyzed by using Cluster Analysis and Multiple Regression Analysis. These are utilized for constructing a much more effective and useful plan building. We have obtained fruitful results. To confirm the findings by utilizing the new consecutive visiting records would be the future works to be investigated.
\end{abstract}

Keywords: Fuji City, area rebirth, regional vitalization, festival, cluster analysis, multiple regression analysis

\section{Introduction}

In recent years in Japan, the national and local governments have been trying to attract foreign tourists by using strategic approaches and developing tourist facilities, with the aim of promoting regional exchange and generating economic benefits. Particular aims of local government are to overcome the common problems of an aging population and declining birthrate through tourism-generated income and to stimulate the local society through regional exchange and migration. However, in order to take measures that will increase tourism, it is necessary to understand the attraction of particular regions in Japan. Moreover, it is necessary to have a picture of the tourists that might want to visit such regions.

In order to investigate solutions to problems shared across regions it is necessary to carefully examine the critical basic data as well as appropriate methods of data collection. To try to obtain such data, preceding studies on tourist destinations that have statistically analyzed trends in tourist behavior will now be reviewed.

Yoshida et al. designed and conducted a visitor survey on the spot, which used a questionnaire to investigate the activities of visitors to the Ueno district in Taito ward, Tokyo. Doi et al. analyzed the image of the Izu Peninsula as a tourist destination in their 2003 study "Questionnaire Survey on the Izu Peninsula." Kano conducted tourist behavior studies in Atami city in 2008, 2009, 2014 and in other years.

Shopping streets at local city in Japan are generally declining. It is because most of them were built in the so-called "High Growth Period (1954-1973)". Therefore they became old and area rebirth and/or regional revitalization are required everywhere.

There are many papers published concerning area rebirth or regional revitalization. Inoue (2017) has pointed out the importance of tourism promotion. Ingu et al. (2017) made a study on the application of geothermal power generation to local revitalization in Obama Town. Kotani (2017) developed the project of shutter art to Wakkanai 
Chuo shopping street in Hokkaido, Japan. Ohkubo (2017) has made a questionnaire research at Jigenji shopping street in Kagoshima Prefecture, Japan and analyzed the current condition and future issues. For about tourism, many papers are presented from many aspects as follows.

In this paper, we handle the area rebirth and/or regional revitalization of shopping street. We focus on Fuji city in Japan. Fuji city is located in Shizuoka Prefecture. Mt. Fuji is very famous all around the world and we can see its beautiful scenery from Fuji city, which is at the foot of Mt. Fuji. There are two big shopping street in Fuji city. One is Yoshiwara shopping street and another one is Fuji shopping street. They became old and building area rebirth and regional revitalization plan have started. Following investigation was conducted by the joint research group (Fuji Chamber of Commerce \& Industry, Fujisan Area Management Company, Katsumata Maruyama Architects, Kougakuin University and Tokoha University). The main project activities are as follows.
A Investigation on the assets which are not in active use
B Questionnaire Investigation to Entrepreneur
C Questionnaire Investigation to the residents and visitors

After that, area rebirth and regional revitalization plan were built.

In this paper, we handle above stated C. Four big festivals are held at Fuji city. Two big festivals are held at Yoshiwara Shopping Street Town and two big festivals at Fuji Shopping Street Town. At Yoshiwara Shopping Street Town, Yoshiwara Gion Festival is carried out during June and Yoshiwara Shukuba (post-town) Festival is held during October. On the other hand, Kinoene Summer Festival is conducted during August and Kinoene Autumn Festival is performed during October at Fuji Shopping Street Town. Many people visit these festivals including residents in that area. Therefore questionnaire investigation of $\mathrm{C}$ is conducted during these periods. Finally, we have obtained 982 sheets (Yoshiwara Shopping Street Town: 448, Fuji Shopping Street Town: 534). Basic statistical analysis, Cluster Analysis and Multiple Regression Analysis are executed based on that.

In this paper, a questionnaire investigation is executed in order to clarify residents and visitors' needs for the shopping street, and utilize them to the plan building of the area rebirth and/or regional revitalization of shopping street. There is a big difference between Fuji Shopping Street Town and Yoshiwara Shopping Street Town. Therefore we focus Fuji Shopping Street Town in this paper. Such multivariate analysis as Cluster Analysis and Multiple Regression Analysis are executed based on that. Some interesting and instructive results were obtained.

The rest of the paper is organized as follows. Outline of questionnaire investigation is stated in section 2. In section 3, Cluster Analysis is executed which is followed by the Multiple Regression Analysis in section 4.

\section{Outline and the Basic Statistical Results of the Questionnaire Research}

\subsection{Outline of the Questionnaire Research}

A questionnaire investigation to the residents and visitors is conducted during these periods in order to clarify residents and visitors' needs for the shopping street, and utilize them to the plan building of the area rebirth and/or regional revitalization of shopping street. The outline of questionnaire research is as follows. Questionnaire sheet is attached in Appendix.

1) Scope of investigation: Residents and visitors who have visited four big festivals at Fuji city in Shizuoka Prefecture, Japan

2) Period: Yoshiwara Gion Festival: June 11, 12/2016; Yoshiwara Shukuba (post-town) Festival: October 9/2016; Kinoene Summer Festival: August 6, 7/2016; Kinoene Autumn Festival: October 15, 16/2016.

3) Method: Local site, Dispatch sheet, Self writing

4) Collection: Number of distribution 700, Number of collection 534(collection rate 76.3\%), Valid answer 534

\subsection{Basic Statistical Results}

Now, we show the main summary results by single variable.

\subsubsection{Sex (Q7)}

Male $43.3 \%$, Female $56.7 \%$

These are exhibited in Figure 1. 


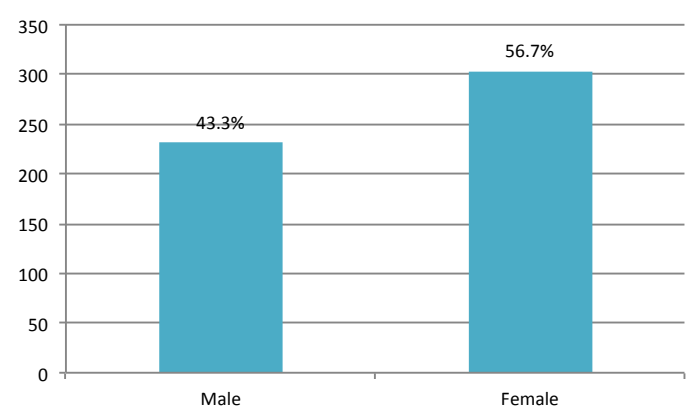

Figure 1. Sex (Q7)

\subsubsection{Age (Q8)}

$10^{\text {th }} 20.6 \%, 20^{\text {th }} 16.7 \%, 30^{\text {th }} 25.3 \%, 40^{\text {th }} 17.0 \%, 50^{\text {th }} 10.1 \%, 60^{\text {th }} 6.9 \%$, More than $703.4 \%$

These are exhibited in Figure 2.

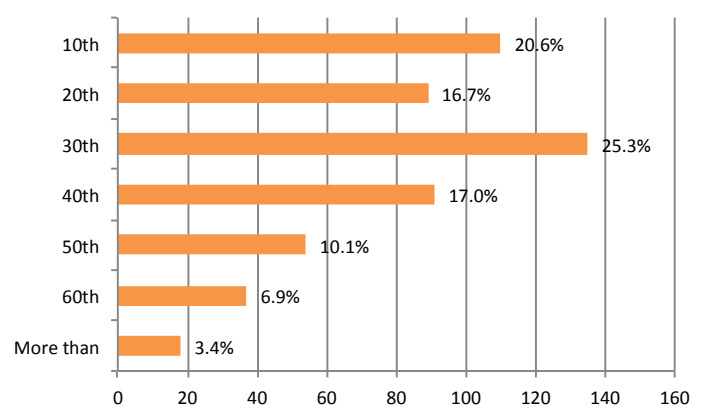

Figure 2. Age (Q8)

\subsubsection{Residence (Q9)}

a. Fuji city $82.8 \%$, b. Fujinomiya city $8.8 \%$, c. Numazu city $2.1 \%$, d. Mishima city $0.7 \%$, e. Shizuoka city $0.9 \%$, F. Else (in Shizuoka Prefecture) 2.1\%, g. Outside of Shizuoka Prefecture 2.6\%

These are exhibited in Figure 3.

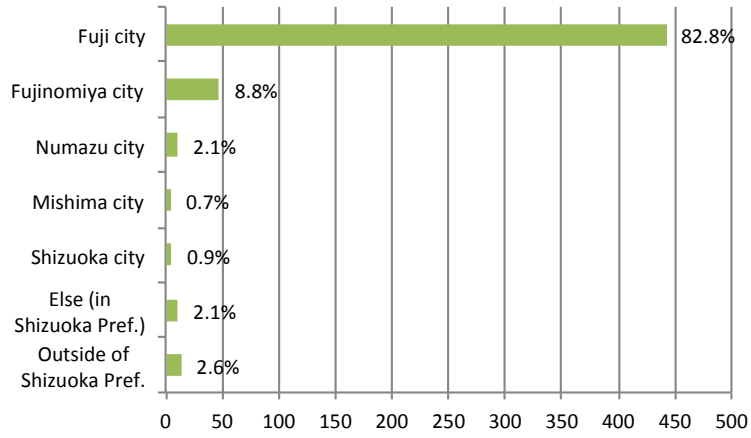

Figure 3. Residence (Q9)

2.2.4 How often do you come to this shopping street? (Q1)

Everyday $21.2 \%$, More than 1 time a week $17.2 \%$, More than 1 time a month $22.7 \%$, More than 1 time a year $26.8 \%$, First time $3.0 \%$, Not filled in $4.1 \%$ 
These are exhibited in Figure 4.

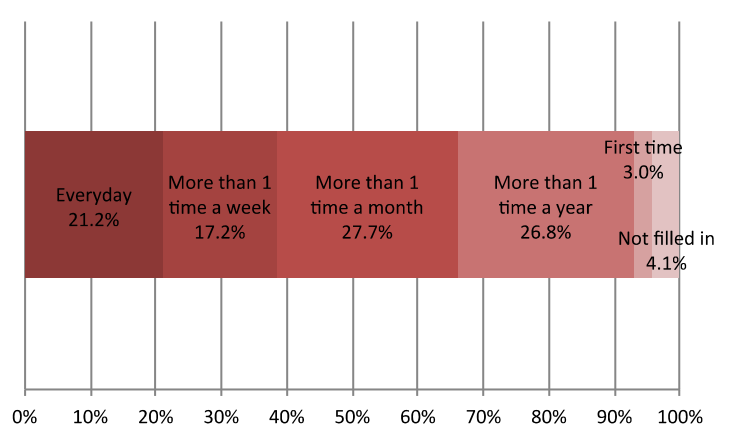

Figure 4. How often do you come to this shopping street? (Q1)

2.2.5 What is the purpose of visiting here? (Q2)

Shopping 17.2\%, Eating and drinking 13.6\%, Business 7.4\%, Celebration, event 34.1\%, Leisure, amusement $6.1 \%$, miscellaneous $21.6 \%$

These are exhibited in Figure 5.

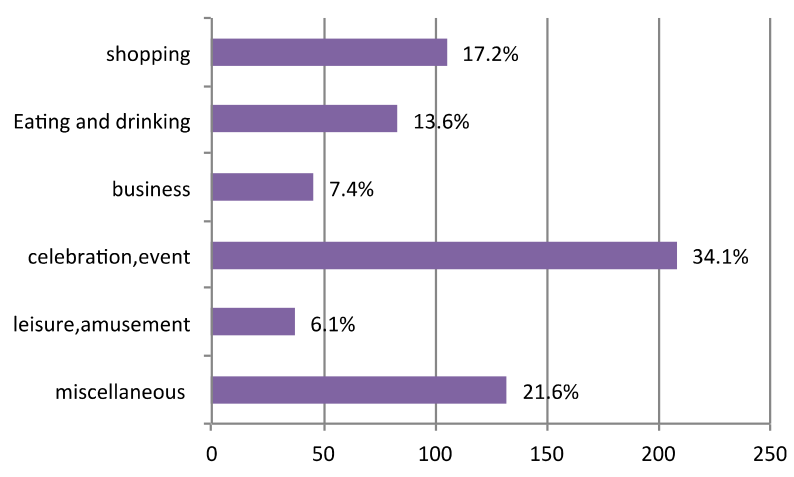

Figure 5. What is the purpose of visiting here? (Q2)

2.2.6 How do you feel about the image of the surrounding area at this shopping street? (Q3)

Beautiful $51.2 \%$, Ugly $48.8 \%$,Of the united feeling there is $44.3 \%$, Scattered $55.7 \%$,Varied $38.5 \%$, Featureless $61.5 \%$, New $37.1 \%$, Historic $62.9 \%$, Full of nature $37.1 \%$, Urban $62.9 \%$, Cheerful $44.1 \%$, Gloomy $55.9 \%$, Individualistic $42.0 \%$, Conventional $58.0 \%$, Friendly $57.8 \%$, Unfriendly $42.2 \%$, Healed $53.3 \%$, Stimulated 46.7\%, Open $44.8 \%$, exclusive $55.2 \%$, Want to reside $43.6 \%$, Do not want to reside $56.4 \%$, Warm $55.1 \%$, Aloof $44.9 \%$, Fascinating $42.1 \%$, Not fascinating $57.9 \%$, Want to play $47.1 \%$, Want to examine deliberately $52.9 \%$, Lively $36.8 \%$, Calm $63.2 \%$, Atmosphere of urban $28.0 \%$,Atmosphere of rural area $72.0 \%$

These are exhibited in Figure 6. 


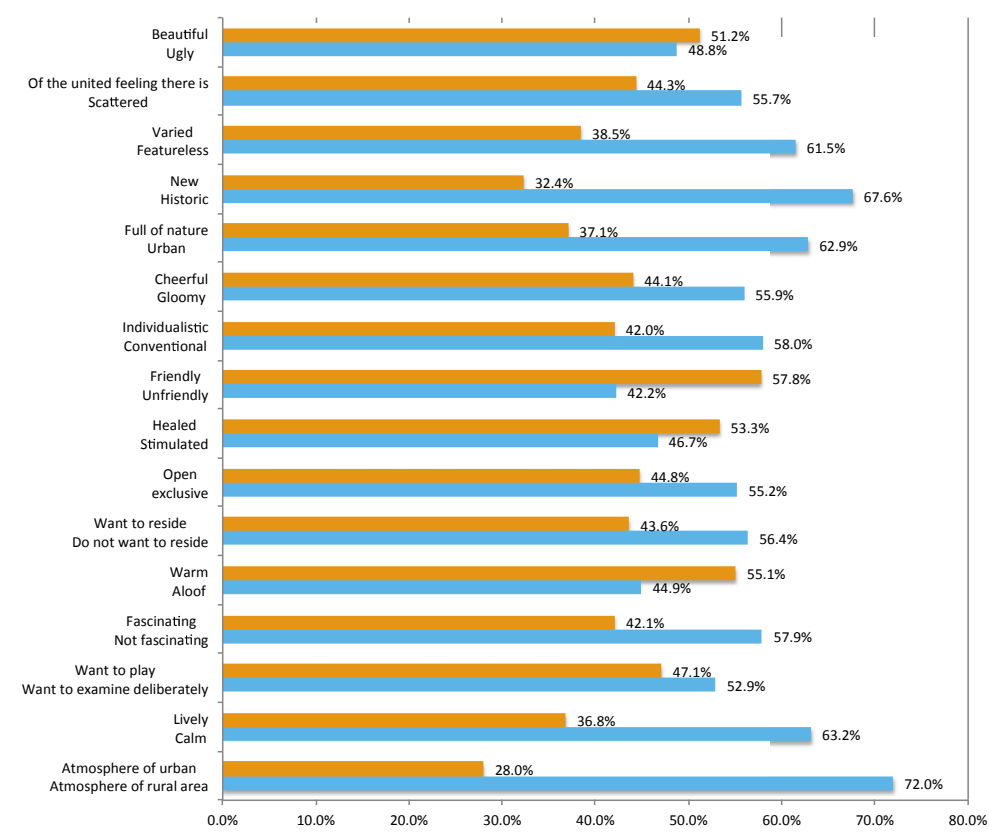

Figure 6. How do you feel about the image of the surrounding area at this shopping street? (Q3)

2.2.7 There are many old building at the age of nearly 50 years. Do you think we can still use them? (Q4) Can use it $48.7 \%$, Cannot use it $29.2 \%$, Have no idea $22.1 \%$

These are exhibited in Figure 7.

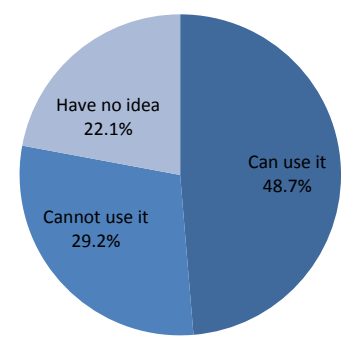

Figure 7. There are many old building at the age of nearly 50 years. Do you think we can still use them? (Q4)

\section{Cluster analysis}

Cluster analysis is executed in order to confirm the relationship/closeness among items. First of all, cluster cohesion process is exhibited in Table 1. 
Table 1. Cluster Cohesion Process

\begin{tabular}{lrrrrrr}
\hline \multirow{2}{*}{ Step } & \multicolumn{2}{c}{ Combined Cluster } & \multirow{2}{*}{ Coefficient } & \multicolumn{2}{c}{ First stage of cluster } & \multirow{2}{*}{ Cluster 1 } \\
Cluster 1 & \multicolumn{1}{c}{ Cluster 2 } & Cluster 2 & Next Step \\
\hline 1 & 6 & 12 & 301.000 & 0 & 0 & 5 \\
2 & 8 & 11 & 617.000 & 0 & 0 & 12 \\
3 & 1 & 2 & 937.000 & 0 & 0 & 10 \\
4 & 14 & 15 & 1292.000 & 0 & 0 & 9 \\
5 & 6 & 10 & 1661.000 & 1 & 0 & 8 \\
6 & 3 & 4 & 2034.000 & 0 & 0 & 9 \\
7 & 5 & 9 & 2427.500 & 0 & 0 & 11 \\
8 & 6 & 7 & 2851.000 & 5 & 0 & 10 \\
9 & 3 & 14 & 3278.000 & 6 & 4 & 14 \\
10 & 1 & 6 & 3727.167 & 3 & 8 & 13 \\
11 & 5 & 13 & 4203.000 & 7 & 0 & 12 \\
12 & 5 & 8 & 4805.267 & 11 & 2 & 13 \\
13 & 1 & 5 & 5561.000 & 10 & 12 & 14 \\
14 & 1 & 3 & 6778.933 & 13 & 9 & 0 \\
\hline
\end{tabular}

Distance is calculated by using Euclidean square distance. Dendrogram by Ward method is exhibited in Figure 8 .

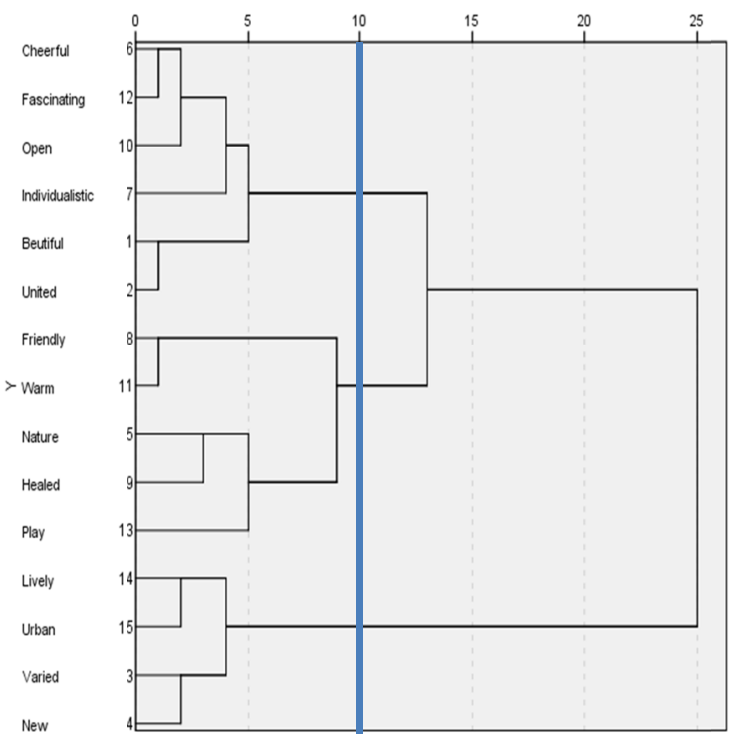

Figure 8. Dendrogram by Ward method

From the results of Cluster Analysis, we can observe three big clusters as follows.

$>\quad /$ Cheerful $\sim$ Of the united feeling there is

$>\quad$ Friendly $\sim$ Want to play

$>$ Lively $\sim$ New

For these clusters, we can name them as follows from its components.

$$
\begin{aligned}
& / \text { Cheerful } \sim \text { Of the united feeling there is } \quad: \text { Beautiful and Attractive } \\
& \begin{array}{ll}
\text { /Friendly } \sim \text { Want to play } & : \text { Warm and Healing } \\
\text { /Lively } \sim \text { New } & : \text { Varied and Urbane }
\end{array}
\end{aligned}
$$

These classification is used in the next Multiple Regression Analysis. 


\section{Multiple Regression Analysis}

Multiple Regression Analysis is executed in order to find the most contributive factor for the specified purpose. The data used are the same with those of Factor Analysis. First of all, Descriptive statistics for the three big clusters which is derived from the Cluster Analysis are exhibited in Table 2. The value of each item in each cluster is summarized and then calculated in statistics.

From the Cluster Analysis, "Want to reside" does not seem to be the regular component, therefore we treat it as an objective function.

Table 2. The Results of Multiple Regression Analysis by 3 Cluster

\begin{tabular}{|c|c|c|c|}
\hline & model 1 & model 2 & model 3 \\
\hline & sig & sig & sig \\
\hline Beautiful and Attractive & $0.498 * *$ & $0.340 * *$ & $0.282 * *$ \\
\hline Warm and Healing & & $0.245 * *$ & $0.253 * *$ \\
\hline Varied and Urbane & & & 0.083 \\
\hline adjusted R-square & $0.247 * *$ & $0.281 * *$ & $0.283 * *$ \\
\hline
\end{tabular}

From Table 2, we can see that the Cluster 1 is best in $\beta$. Therefore we select "Beautiful and Attractive" Cluster and examine it in detail.

Table 3. The Results of Multiple Regression Analysis for each variable in "Beautiful and Attractive" Cluster

\begin{tabular}{|c|c|c|c|}
\hline & model 1 & model 2 & model 3 \\
\hline & sig & sig & sig \\
\hline Open & $0.498 * *$ & $0.340 * *$ & $0.334 * *$ \\
\hline Fascinating & & $0.245 * *$ & $0.220 * *$ \\
\hline Cheerful & & & 0.039 \\
\hline Individualistic & & & 0.031 \\
\hline Beautiful & & & 0.071 \\
\hline United & & & -0.014 \\
\hline adjusted R-square & $0.235 * *$ & $0.289 * *$ & $0.290 * *$ \\
\hline
\end{tabular}

Looking at this table in detail, we can observe that the most influential factor for "Want to reside" is "Open" and then "Fascinating" follow. These results coincide with those of Bayesian Network Analysis we have conducted before.

Thus we could derive the influential/contributive factor (Independent variable) to the specified purpose (Objective function) by utilizing Cluster Analysis and Multiple Regression Analysis.

\section{Conclusion}

Shopping streets at local city in Japan became old and are generally declining. In this paper, we handle the area rebirth and/or regional revitalization of shopping street. We focus on Fuji city in Japan. Four big festivals are held at Fuji city (two for Fuji Shopping Street Town and two for Yoshiwara Shopping Street Town). Many people visit these festivals including residents in that area. There is a big difference between Fuji Shopping Street Town and Yoshiwara Shopping Street Town.

Therefore we focus Fuji Shopping Street Town in this paper. A questionnaire investigation to the residents and visitors is conducted during these periods in order to clarify residents and visitors' needs for the shopping street, and utilize them to the plan building of the area rebirth and/or regional revitalization of shopping street. These are analyzed by using Cluster Analysis and Multiple Regression Analysis. 
The results for Cluster Analysis are as follows. From the results of Cluster Analysis, we can observe three big clusters as follows.

$>\quad /$ Cheerful $\sim$ Of the united feeling there is

$>\quad$ Friendly $\sim$ Want to play

$>\quad /$ Lively $\sim$ New

For these clusters, we can name them as follows from its components.

$$
\begin{aligned}
& / \text { Cheerful } \sim \text { Of the united feeling there is } \quad: \text { Beautiful and Attractive } \\
& \begin{array}{ll}
\text { /Friendly } \sim \text { Want to play } & : \text { Warm and Healing } \\
\text { /Lively } \sim \text { New } & : \text { Varied and Urbane }
\end{array}
\end{aligned}
$$

These classification is used in the next Multiple Regression Analysis.

The results for Multiple Regression Analysis are as follows. Looking at the coefficient table in detail, we can observe that the most influential factor for "Want to reside" is "Open" and then "Fascinating" follow. This will be applied to other shopping street in Japan. The concrete methods to attack this would be different in each place and it should be investigated consecutively. These results coincide with those of Bayesian Network Analysis we have conducted before. Thus we could derive the influential/contributive factor (Independent variable) to the specified purpose (Objective function) by utilizing Cluster Analysis and Multiple Regression Analysis.

There is a limitation in this research that the research period is restricted during the festival time. As for this, the questionnaire investigation should be executed in the plural years and should be analyzed. Further study on this will bring forth much more exquisite analysis.

These are utilized for constructing a much more effective and useful plan building. Although it has a limitation that it is restricted in the number of research, we could obtain the fruitful results. To confirm the findings by utilizing the new consecutive visiting records would be the future works to be investigated.

\section{Acknowledgements}

The authors are grateful to all those who supported us for answering the questionnaire investigation.

\section{References}

Atami city. (2015). 2014 Survey of Tourist Behavior.

Doi, H. (2009). Evaluation of policies to build tourist destinations and statistical analysis. Nippon Hyoron Sha.

Ingu, S., Uemura, M., Uchida, Y., Omiya, M., Miura, T., \& Hironori, H. (2017). A study on the application of geothermal power generation to local revitalization in Obama Town, Unzen City: in consideration of futurability in Obama. Environmental Science Research, Nagasaki University, 20(1), 51-63.

Inoue, A. (2017). Changes in Local Communities Brought by Municipal Mergers: From the Viewpoint of Tourism Promotion as the Main Industry. Bulletin of the Faculty of Regional Development Studies, 2, 1-32. Otemon Gakuin University.

Japan Tourism Agency. (2015). Research study on economic impacts of tourism in Japan 2013, pp. 3.

JNTO. (2015). Practical Travel Guide-410. Izu peninsula, Fuji-hakone-Izu National Park. Retrieved from https://www.jnto.go.jp/eng/location/rtg/pdf/pg-410.pdf\#search='Izupeninsula'

Kano, M. (2011). Characteristic analysis of Atami tourists: Reconsideration based on data add and modify. Shizuoka Economic Research, 16(2), 61-78. Shizuoka University.

Kawazu. (2011). Retrieved from http://www.kawazu-onsen.com/eng/

Kotani, A. (2017). The implementation report of the Machi-lab shutter art project. Bulletin of Wakkanai Hokusei Gakuen University, 17, 207-218.

Ohkubo, Y. (2017). Current status and problems in Jigenji-dori shopping area : from a consumer questionnaire. Bulletin of Local Research, 44(2), 1-15. Kagoshima International University.

Shioya, H. (2009). Overview and application of tourism statistics: Analysis using statistical survey on overnight travels. Journal of Economic Structures, 17(1-2), 16-29. Pan Pacific Association of Input-Output Studies. 
Takeyasu, K., et al. (2010). Modern Marketing. Chuoukeizaisha Publishing.

Yoshida, I. (2009). Consideration on the Characteristic of Visitors' Activity and the Research Method for Tourist Visitors in Urban Areas.

\section{Appendix 1. Questionnaire Sheet about the Image Around the Shopping Street}

1. How often do you come to this shopping street?
a. Everyday
b. ( ) times a week
c. ( ) times a month
d. ( ) times a year
e. miscellaneous
(

2. What is the purpose of visiting here? (Plural answers allowed)
a. shopping b. eating and drinking
c. business
d. celebration, event
e. leisure, amusement f. miscellaneous (

3. How do you feel about the image of the surrounding area at this shopping street? Select the position.

\begin{tabular}{|c|c|c|c|c|c|c|}
\hline Beautiful & - & • & • & • & • & Ugly \\
\hline Of the united feeling there is & • & • & • & • & • & Scattered \\
\hline Varied & - & • & • & - & $\cdot$ & Featureless \\
\hline New & - & - & - & - & - & Historic \\
\hline Full of nature & - & - & - & • & - & Urban \\
\hline Cheerful & - & - & • & • & $\cdot$ & Gloomy \\
\hline Individualistic & • & - & • & • & • & Conventional \\
\hline Friendly & - & • & - & - & - & Unfriendly \\
\hline Healed & - & • & - & - & $\cdot$ & Stimulated \\
\hline Open & • & • & - & - & - & exclusive \\
\hline Want to reside & - & • & - & - & - & Do not want to reside \\
\hline Warm & - & • & - & - & $\cdot$ & Aloof \\
\hline Fascinating & • & - & - & • & • & Not fascinating \\
\hline Want to play & - & - & - & • & - & Want to examine deliberately \\
\hline Lively & • & - & - & - & - & Calm \\
\hline Atmosphere of urban & - & • & . & . & . & Atmosphere of rural area \\
\hline
\end{tabular}

4. There are many old building at the age of nearly 50 years. Do you think we can still use them?
a. Can use it
b. Cannot use it
C. Have no idea

5. Is there any functions or facilities that will be useful?

6. Comments

7. Sex
a. Male
b. Female

8. Age
a.10th b.20th
c.30th
d.40th e.50th f.6th
g. More than 70

9. Residence 
a. Fuji City b. Fujinomiya City c. Numazu City d. Mishima City e. Shizuoka City f. Miscellaneous in Shizuoka Prefecture g. Outside of Shizuoka Prefecture (

\section{Copyrights}

Copyright for this article is retained by the author(s), with first publication rights granted to the journal.

This is an open-access article distributed under the terms and conditions of the Creative Commons Attribution license (http://creativecommons.org/licenses/by/4.0/). 